\title{
Septic syndrome within internal medicine units: finally we have our records!
}

\author{
Antonino Mazzone, ${ }^{1}$ Mauro Campanini ${ }^{2}$ \\ ${ }^{1}$ Medical Area Department, Hospital of Legnano (MI); ${ }^{2}$ Medical Department, University Hospital Maggiore della Carità, \\ Novara, Italy
}

\section{Presentation}

Sepsis is a complex clinical syndrome, difficult to manage, characterized by a severe prognosis and burdened by high mortality (30-40\% for severe sepsis, $45-$ $60 \%$ for septic shock) ${ }^{1-5}$ The estimated impact of septic syndrome (SS) in Europe is 90 cases for every 100,000 inhabitants, progressively increasing, both for the increased awareness of the sepsis problem and consequent heightened refinement of diagnostic procedures, and because of the changed characteristics of the population (average age increase, greater survival of patients suffering from debilitating chronic diseases, increased use of intravascular devices and indwelling bladder catheters, larger indications for immunosuppressive treatment) ${ }^{6-9}$ More and more often this phenomenon concerns the departments of Internal Medicine (IM), much more than those of intensive care units (ICUs) but frequently sepsis patients were admitted in Internal Medicine Units, as evidenced by increasing number of beds occupied by several elderly patients with sepsis in the Internal Medicine wards. ${ }^{10,11}$ SS significantly contributes to the increase in healthcare expenditure and hospitalization costs through an economic engagement, lately estimated at 7.6 billions in Europe and 17.4 bil-

Correspondence: Antonino Mazzone, Medical Area Department, Hospital of Legnano, via Papa Giovanni Paolo II, 20025 Legnano (MI), Italy.

Tel: +39.331.449305 - +39.331.449211

E-mail: antonino.mazzone@asst-ovestmi.it

Key words: Septic syndrome; internal medicine.

Received for publication: 6 October 2016.

Accepted for publication: 20 October 2016.

This work is licensed under a Creative Commons Attribution NonCommercial 4.0 License (CC BY-NC 4.0).

(C) Copyright A. Mazzone and M. Campanini, 2016

Licensee PAGEPress, Italy

Italian Journal of Medicine 2016; 10:253-254

doi:10.4081/itjm.2016.789 lions Euros in the United States. ${ }^{10-12}$ Several studies have been carried out at international level in order to assess the costs of the management of patients with sepsis, both in ICU and other hospital wards. In the Italian context, studies highlight the lack of current assessments of running costs of this pathology, strictly conducted within a medical environment. Sepsis is an inflammatory disease, commonly diagnosed in Internal Medicine units, with a very high morbidity and mortality rate. From a series of epidemiological studies published in the last years is evident a considerable increase in the incidence of this condition. ${ }^{1-4}$ All information about epidemiology, management and prognosis derived from the same studies carried out in intensive care, is that there are very few observational and prospective studies that deal with sepsis in wards other than ICUs, such as Internal Medicine departments. Despite all this, a growing number of retrospective observations shows that patients with sepsis, and severe sepsis too, are regularly admitted in Internal Medicine wards, without the request for the ICU support. Unfortunately, only few data are available about the epidemiology management and prognosis of sepsis patients admitted to the Internal Medicine wards. Many studies report a significant increase in mortality in patients with sepsis or severe sepsis when not admitted to an intensive care setting. Most of these studies are retrospective and were performed before the implementation of the guidelines on the management of sepsis, severe sepsis and septic shock. ${ }^{12}$ Information on sepsis management outside of intensive care is very limited. Only a few studies provided data on the clinical history of sepsis within internal Medicine units. In order to bridge this gap the Federation of Associations of Hospital Doctors on Internal Medicine (FADOI) performed a specific study, aimed to assess the shortterm mortality and to evaluate the prognostic risk factors in a large cohort of septic patients treated in internal medicine units, evaluating the diagnosis and treatment of types of bacteria involved in SS in Internal Medicine. ${ }^{13}$ Thirty-one Italian internal medicine units participated in the study. Within each participating unit, all admitted patients were screened for the presence of 
sepsis. A total of 533 patients were included (average age 73.3 years, $50.8 \%$ males); 78 patients $[14.6 \%, 95 \%$ confidence interval (CI) 11.9, 18.0\%] died during hospitalization; mortality rate was $5.5 \%$ (95\% CI 3.1 , $9.6 \%$ ) in patients with non-severe sepsis and $20.1 \%$ $(95 \%$ CI $16.2,28.8 \%)$ in patients with severe sepsis or septic shock. 316 patients were suffering from severe sepsis and 17 from a septic shock 17 . Sepsis was most commonly related to urinary tract $(30.8 \%)$ and respiratory infections $(26.5 \%) .94 \%$ of patients had another comorbidity, mostly: $63 \%$ cardiovascular and $30 \%$ diabetes. The 626 positive blood cultures showed a predominance of Escherichia coli and secondly Staphylococcus aureus and epidermidis infections. Multivariate analysis showed that sepsis by E. coli has a good prognosis. Severe sepsis or septic shock [odds ratio (OR) 4.41, 95\% CI 1.93, 10.05], immune system weakening (OR 2.10, 95\% CI 1.12, 3.94), active solid cancer (OR 2.14, 95\% CI 1.16, 3.94), and age (OR 1.03 per year, $95 \%$ CI 1.01, 1.06) were significantly associated with an increased mortality risk, whereas blood culture positive for $E$. coli was significantly associated with a reduced mortality risk (OR $0.46,95 \%$ CI 0.24 , 0.88 ). In-hospital mortality of septic patients treated in internal medicine units appeared similar to the mortality rate obtained in recent studies conducted in the ICU setting. ${ }^{9-13}$

\section{Conclusions}

This supplement just fits the need to increase the sensitivity of Internal Medicine doctors about the best clinical management of SS patients, due to the significant epidemiological increase in these complex patients, mostly with many coexisting comorbidities. We have to consider the diagnostic and therapeutic process also from an economic point of view, according to the usual competence and activities in Internal Medicine. Just nowadays many of these patients are managed in the departments of Internal Medicine, but with far fewer resources than in the ICUs.

\section{References}

1. Angus DC, van der Poll T. Severe sepsis and septic shock. N Engl J Med 2013;369:840-51.
2. Angus DC, Linde-Zwirble WT, Lidicker J, et al. Epidemiology of severe sepsis in the United States: analysis of incidence, outcome, and associated costs of care. Crit Care Med 2001;29:1303-10.

3. Sundararajan V, Macisaac CM, Presneill JJ, et al. Epidemiology of sepsis in Victoria, Australia. Crit Care Med 2005;33:71-80.

4. Martin GS, Mannino DM, Eaton S, et al. The epidemiology of sepsis in the United States from 1979 through 2000. N Engl J Med 2003;348:1546-54.

5. Vincent JL, Rello J, Marshall J, et al. EPIC II Group of Investigators. International study of the prevalence and outcomes of infection in intensive care units. JAMA 2009;302:2323-9.

6. Levy MM, Fink MP, Marshall JC, et al. International Sepsis Definitions Conference, $2001 \mathrm{SCCM} / \mathrm{ES} / \mathrm{CM} /$ ACCP/ATS/SIS International Sepsis Definitions Conference. Intensive Care Med 2003;29:530-8.

7. Lagu T, Rothberg MB, Shieh MS, et al. Hospitalizations, costs, and outcomes of severe sepsis in the United States 2003 to 2007. Crit Care Med 2012;40:754-61.

8. Dellinger RP, Levy MM, Rhodes A, et al. Surviving Sepsis Campaign Guidelines Committee including The Pediatric Subgroup, Surviving Sepsis Campaign: international guidelines for management of severe sepsis and septic shock, 2012. Intensive Care Med 2013;39: 165-228.

9. Esteban A, Frutos-Vivar F, Ferguson ND, et al. Sepsis incidence and outcome: contrasting the intensive care unit with the hospital ward. Crit Care Med 2007;35: 1284-89.

10. Vardi M, Ghanem-Zoubi NO, Bitterman H, et al. Sepsis in nonagenarians admitted to internal medicine departments: a comparative study of outcomes. QJM 2013; 106:261-6.

11. Young MP, Gooder VJ, McBride K, et al. Inpatient transfers to the intensive care unit: delays are associated with increased mortality and morbidity. J Gen Intern Med 2003;18:77-83.

12. Dellinger RP, Levy MM, Carlet JM, et al. Surviving Sepsis Campaign: international guidelines for management of severe sepsis and septic shock: 2008. Intensive Care Med 2008;34:17-60.

13. Mazzone A, Dentali F, La Regina M, et al. Clinical features, short-term mortality, and prognostic risk factors of septic patients admitted to internal medicine units: results of an Italian multicenter prospective study. Medicine 2016;95:e2124. 